\title{
An assessment of surgical outcome with the influencing factors of horizontal strabismus surgery
}

\author{
Saraswati Pandey ${ }^{1}$, Araniko Pandey², Kabindra Bajracharya ${ }^{3}$, Hari B Thapa ${ }^{4}$, \\ Shakti Shrestha ${ }^{5}$, Arjun M Bhari' ${ }^{6}$, Salma KC Rai ${ }^{7}$ \\ ${ }^{1}$ Pediatric Ophthalmologist, ${ }^{2}$ Ophthalmologist, ${ }^{3}$ Assistant Professor and Pediatric Ophthalmologist, ${ }^{4}$ Optometrist, \\ ${ }^{6}$ Pediatric Ophthalmologist, ${ }^{7}$ Professor and Pediatric Ophthalmologist, Department of Pediatric Ophthalmology and \\ Strabismus, Lumbini Eye Institute, Bhairahawa, Nepal, ${ }^{5}$ Assistant Professor, Department of Pharmacy, Shree Medical \\ and Technical College, Bharatpur, Nepal
}

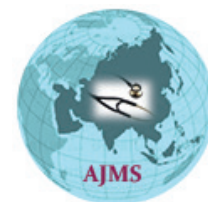

A B S TR A C T

Background: Influencing factors of conventional horizontal surgery for surgical outcome has not been assessed in Nepal. Aims and Objective: To assess the pre-operative factors that influences the surgical outcome of horizontal strabismus surgery. Materials and Methods: The medical records of 68 patients who underwent their first horizontal strabismus surgery at Lumbini Eye Institute from $1^{\text {st }}$ January to $30^{\text {th }}$ December 2015 were retrospectively reviewed. The collected clinical data included diagnosis, age group, visual acuity, binocular function, extraocular motility and pre and postoperative deviation. The success of surgery was defined by eye deviation less than 10 prism diopters (PD) at 6 weeks after operation. The influencing factors for surgical success (diagnosis, age group, visual acuity, binocular function, and angle deviations) were analyzed using chi square test and Mann-Whitney - U test, where ever appropriate. Results: Out of 113 patients who underwent strabismus surgery during the year, 68 patients were enrolled in the study. Majority of the patients $(27,39.7 \%)$ were $>9$ years of age and $52.9 \%$ were female. Thirty seven patients $(54.4 \%)$ were esotropic whereas, 31 were exotropic. Preoperatively, angle of deviation ranged from 20 to 90 PD with binocular vision present in $57.4 \%$ cases. Overall, success was seen in 26 patients (38.2\%). Pre-operative angle of deviation and binocular vision had statistical significance with surgical success ( $p=0.012$ and 0.026 respectively). Conclusion: Larger angle of deviation and poor binocular vision at presentation has higher failure rate for horizontal strabismus surgery.

Key words: Strabismus, Strabismus surgery, Binocular vision
http://nepjol.info/index.php/AJMS DOI: 10.3126/ajms.v8i5.17634 E-ISSN: 2091-0576 P-ISSN: 2467-9100

\section{INTRODUCTION}

Strabismus is a common problem in ophthalmology and the prevalence ranges from $3 \%$ to $5 \% \cdot{ }^{1-4}$ The management involves careful assessment of patients, treatment of amblyopia, refractive errors and surgery. The first documented surgical treatment for strabismus occurred in 1839 and was performed by Johann Friederich Dieffenbach, a general surgeon. ${ }^{5}$

Strabismus surgery is an effective treatment, particularly in cases where conservative methods have failed. Post surgical ocular alignment of visual axis will be improved along with stereopsis, in some patients, especially in intermittent deviation of recent onset. The surgery can eliminate double vision, improve three dimensional visions, expand visual field, eliminate abnormal head posture, improve psychological function, and improve vocation status.

There is paucity of data on the outcomes of conventional surgery in Nepal but several studies in other countries have reported outcomes and success rates for strabismus surgery ranging from $30 \%$ to $80 \% .^{6-10}$ Our study is probably the 
first attempt to document the evidence of this surgery and its outcome from Nepal.

\section{MATERIALS AND METHODS}

The medical records of 68 patients who underwent their first horizontal strabismus surgery at Lumbini Eye Institute, Bhairahawa, Nepal from $1^{\text {st }}$ January to $30^{\text {th }}$ December 2015 were retrospectively reviewed after an approved from the Research Committee of Lumbini Eye Institute. Patients with restrictive muscular disease or neuromuscular junction disease were excluded from the study.

The collected clinical data included diagnosis, age group, visual acuity, binocular function, extraocular motility and pre and postoperative deviation. Visual acuity was measured by LogMAR chart ( $\mathrm{E}$ and lea symbol) but in preverbal children was assessed by the CSM method. Binocular function was evaluated by Titmus fly test, Random dot and Worth-four dot test. Angles of deviation were evaluated by prism cover test and modified Krimsky test. The patients were divided into two age groups; the first group was 9 years or less and the second group was over 9 years. The distribution of age group was due to concern of efficiency of amblyopia treatment at different ages. Guidelines in planning surgical amounts for esotropia and exotropia were based on Marshall Park's formula.

The success of surgery was defined by eye deviation less than 10 prism diopters at 6 weeks after operation. The influencing factors for surgical success (diagnosis, age group, visual acuity, binocular function, and angle deviations) were analyzed using chi square test and Mann-Whitney U test where appropriate. Normality testing for distribution of data was done by Kolmogorov-Smirnov test. All the data were entered and analysed in SPSS version 20.

\section{RESULTS}

Demographic profile and clinical parameters of the study population is shown in Table 1. One hundred and thirteen patients underwent strabismus surgery during the year, among which 68 patients with horizontal strabismus surgery were enrolled in the study. Majority of the patients $(27,39.7 \%)$ were $>9$ years of age and $52.9 \%$ were female. Strabismus surgery for patient as early as 2 years was done. Thirty seven patients were esotropic (ET) whereas, 31 were exotropic (XT). Preoperatively, angle of deviation ranged from 20 to 90 PD with binocular vision present in $57.4 \%$ cases. Overall, success was seen in 26 patients $(38.2 \%)$.

The influencing factors of successful surgery were analyzed by bivariate analysis (Table 2). There was statistically significant difference in the pre-operative angle of deviation between those whose surgery was successful and unsuccessful at $\mathrm{p}=0.012$. The median angle of deviation was lesser in surgery that was successful as compared to failed cases (45 verses 50 ). Similarly, the preoperative binocular function was significantly associated with the surgical outcome at $\mathrm{p}=0.026$. Most of the individuals who had no pre-operative binocular function had unsuccessful surgery $(29,74 \%)$. Moreover, higher percentage of successful cases $(55 \%)$ had presence of pre-operative binocular function.

Other parameters such as diagnosis, age group and preoperative VA were not statistically significant with surgical outcome.

\begin{tabular}{|c|c|c|c|}
\hline \multirow{2}{*}{$\begin{array}{l}\text { Characteristics } \\
\text { Age (years) }\end{array}$} & \multirow{2}{*}{$\begin{array}{l}\text { Categories } \\
0-9\end{array}$} & \multicolumn{2}{|c|}{ Number of cases=68 N (\%) } \\
\hline & & 27 & $(39.7)$ \\
\hline & $>9$ & 41 & $(60.3)$ \\
\hline & Median, IQR (min, max) & $10.0,7$ & $(2,18)$ \\
\hline \multirow[t]{2}{*}{ Sex } & Male & 32 & (47.1) \\
\hline & Female & 36 & (52.9) \\
\hline \multirow[t]{2}{*}{ Diagnosis } & Esotropia & 37 & $(54.4)$ \\
\hline & Exotropia & 31 & $(45.6)$ \\
\hline \multirow[t]{3}{*}{ Laterality } & RE & 32 & $(47.1)$ \\
\hline & LE & 30 & (44.1) \\
\hline & $\mathrm{BE}$ & 6 & $(8.8)$ \\
\hline \multirow[t]{2}{*}{ Pre-op angle of deviation (Prism Dioptre) } & Median (IQR) & 45.00 & (15) \\
\hline & Min, Max & 20,90 & \\
\hline \multirow[t]{2}{*}{ Pre-op binocular function } & Present & 29 & (42.6) \\
\hline & Absent & 39 & (57.4) \\
\hline \multirow[t]{2}{*}{ Pre-op VA (log MAR) } & Median (IQR) & 0.3200 & (1.00) \\
\hline & Min, Max & 0.00 & (1.78) \\
\hline \multirow[t]{2}{*}{ Success } & Yes & 26 & $(38.2)$ \\
\hline & No & 42 & $(61.8)$ \\
\hline
\end{tabular}




\begin{tabular}{|c|c|c|c|}
\hline \multirow[t]{2}{*}{ Parameters } & \multicolumn{2}{|c|}{ Surgical outcome n (\%) } & \multirow[t]{2}{*}{$p$ value } \\
\hline & Success & Failure & \\
\hline \multicolumn{4}{|l|}{ Diagnosis } \\
\hline Esotropia & $18(49)$ & $19(51)$ & $0.093^{c}$ \\
\hline Exotropia & $8(26)$ & $31(74)$ & \\
\hline \multicolumn{4}{|l|}{$\begin{array}{l}\text { Pre-operative } \\
\text { binocular function }\end{array}$} \\
\hline Present & $16(55)$ & $13(44)$ & $0.026^{* C}$ \\
\hline Absent & $10(25)$ & $29(74)$ & \\
\hline $\begin{array}{l}\text { Pre-operative angle } \\
\text { of deviation§ }\end{array}$ & $45(20)$ & $50(20)$ & $0.012^{* m}$ \\
\hline \multicolumn{4}{|l|}{ Age groups } \\
\hline $0-9$ yrs & $11(41)$ & $16(49)$ & $0.928^{C}$ \\
\hline$>9$ yrs & $15(37)$ & $26(63)$ & \\
\hline $\begin{array}{l}\text { Pre-operative visual } \\
\text { acuity§}\end{array}$ & $0.26(1.00)$ & $0.46(1.01)$ & $0.093^{m}$ \\
\hline
\end{tabular}

\section{DISCUSSION}

The success rate of horizontal strabismus surgery in our study was 38.2\% (49\% for ET, 26\% XT). Failure was higher $(74 \%)$ in XT, though no statistical significance was seen. We had presumed surgical success to be angle of deviation $<10 \mathrm{PD}$ at 6 weeks after surgery.

Study reported by various authors have shown the surgical outcome to be ranging from $56.3 \%-81.25 \%$ for horizontal strabismus surgery. ${ }^{8,9,11-13}$ A study done by Min Yang et al showed a lower surgical success for patients undergoing 2 muscles (30\%) and 3 muscles $(26.7 \%)$ surgery for large angle intermittent exotropia. ${ }^{14}$ Also, another study showed a success of $42.9 \%$ in large angle constant exotropia $>=80 \mathrm{PD}$ undergoing 3 muscles single staged horizontal muscle surgery. ${ }^{15}$

In our study, pre-op binocular function was absent in $57.4 \%$ of patients, which was statistically significant as an influencing factor for surgical success $(\mathrm{P}=0.026)$. Similarly, $37 / 68(54.4 \%)$ patients had pre-op angle of deviation of 40-50 PD which was also statistically significant as an influencing factor $(\mathrm{P}=0.012)$.

The difference in the results of success could be related to different surgical techniques, number of muscles operated, the criteria of the residual strabismus, influencing factors, follow up period and experience of the surgeon.

Pre-op angle of deviation was shown to have statistical significance with the surgical outcome in our study, which was similar with studies presented by various authors. ${ }^{8,9,12,13}$ Lower surgical success for large angle deviation has also been presented in few studies. ${ }^{14,15}$
Pre-op binocular vision was a significant influencing factor, which was similar to other studies. ${ }^{9,12}$ Contrasting results to this has also been presented in various scientific papers. ${ }^{8,11}$

Other influencing factors like; age group, diagnosis and pre-op VA were not significant as an influencing factor in our study. This was similar to some of the literatures reviewed by our team. ${ }^{11,14}$ Age group of $>9$ yrs had a rate of 26/41 (63\%) of failure, but it was still not statistically significant. Study done by Kampanartsanyakorn et al showed a statistically lower success for patients undergoing surgery over 6 years of age whereas diagnosis and pre-op VA was not significant. ${ }^{8}$

\section{CONCLUSION}

Pre-op angles of deviation and binocular vision were found to be good predictors as an influencing factors for surgical outcome in our study. This shows that, larger angle of deviation and poor binocular vision at presentation has higher failure rate for horizontal strabismus surgery.

\section{REFERENCES}

1. Abrahamsson M, Magnusson $\mathrm{G}$ and Sjöstrand J. Inheritance of strabismus and the gain of using heredity to determine populations at risk of developing strabismus. Acta Ophthalmol Scand 1999; 77: 653-657.

2. Arora A, Williams B, Arora AK, McNamara R, Yates $\mathrm{J}$ and Fielder A. Decreasing strabismus surgery. $\mathrm{Br} \mathrm{J}$ Ophthalmol 2005; 89: 409-412.

3. Graham PA. Epidemiology of strabismus. Br J Ophthalmol 1974; 58: 224-231.

4. Preslan MW and Novak A. Baltimore Vision Screening Project. Ophthalmology 1996; 103: 105-109.

5. Cooper $\mathrm{J}$ and Medow N. Major review, Intermittent Exotropia, Basic and Divergence Excess Type. Binocular Vision \& Eye Muscle Surgery Qtrly 1993; 8: 185-216.

6. Crouch ER. A comparison of the success rates of resident and attending strabismus surgery: discussion. J Pediatr Ophthalmol Strabismus 1993; 30: 157-158.

7. Forrest MP, Finnigan S and Gole GA. Three horizontal muscle squint surgery for large angle infantile esotropia. Clin Experiment Ophthalmol 2003; 31: 509-516.

8. Kampanartsanyakorn S, Surachatkumtonekul T, Dulayajinda D, Jumroendararasmee $\mathrm{M}$ and Tongsae $\mathrm{S}$. The outcomes of horizontal strabismus surgery and influencing factors of the surgical success. J Med Assoc Thail Chotmaihet Thangphaet 2005; 88 Suppl 9: S94-S99.

9. Segal ZI, Rehany $U$ and Rumelt S. Measurements for horizontal extraocular muscle surgery from the suture site: outcome and influencing factors. Eye Lond Engl 2000; 14: 879-883.

10. Von NKG. Binocular vision and ocular motility: theory and management of strabismus, $5^{\text {th }}$ ed. ed. Mosby, St. Louis, Sydney. 1996.

11. Ganguly $S$ and Pradhan R. Effect of monocular surgery for large-angle horizontal deviation in adults. Nepal J Ophthalmol 
2011; 3: 27-30.

12. Gogate PM, Rishikeshi N, Taras S, Aghor M and Deshpande MD. Clinical audit of horizontal strabismus surgery in children in Maharashtra, India. Strabismus 2010; 18: 13-17.

13. Sharma AK, Thapa M, Shrestha GB, Sitaula S and Shrestha GS. Outcome of horizontal strabismus surgery and parents' satisfaction. Nepal J Ophthalmol 2014; 6: 162-169.
14. Yang M, Chen J, Shen T, Kang Y, Deng D, Lin X, et al. Single Stage Surgical Outcomes for Large Angle Intermittent Exotropia. PLoS ONE 11. 2016.

15. Lau FHS, Fan DSP, Yip WWK, Yu CBO and Lam DSC. Surgical outcome of single-staged three horizontal muscles squint surgery for extra-large angle exotropia. Eye Lond Engl 2010; 24: 1171-1176.

\section{Authors Contribution:}

SP - Concept, design of the study, reviewed literature, collected data, manuscript preparation, editing and revision of the manuscript; AP - Reviewed literature, manuscript preparation; KB - Concept, editing of the manuscript; HBT - Design, literature review; SS - Statistical analysis; AMB - Review literature, editing of the manuscript; SKC - Concept, initial manuscript preparation.

Dr Saraswati Pandey:- (i) http://orcid.org/0000-0002-8206-9217

Dr Araniko Pandey:- (1) http://orcid.org/0000-0002-0791-293X

Dr Kabindra Bajracharya:- (1) http://orcid.org/0000-0002-1742-9220

Mr Hari Bahadur Thapa:- (D) http://orcid.org/0000-0002-2132-0666

Mr Shakti Shrestha:- http://orcid.org/0000-0003-0344-091X

Dr Arjun Malla Bhari:- (1) http://orcid.org/0000-0003-2753-5155

Dr Salma KC Rai:- (1) http://orcid.org/0000-0001-5559-1512

Source of Support: Nil, Conflict of Interest: None declared. 